\title{
AVALIAÇÃO DA INFLUÊNCIA DE ATIVIDADES DE EDUCAÇÃO AMBIENTAL NA MELHORIA DA COLETA SELETIVA EM UMA INSTITUIÇÃO DE ENSINO
}

\author{
Ana Carolina Moraes Campos ${ }^{1}$ \\ André Geraldo Cornélio Ribeiro ${ }^{2}$ \\ Magda Carvalho Pires ${ }^{3}$ \\ Felipe Amourim Sousa ${ }^{4}$
}

Resumo: As instituições de ensino impactam significativamente o meio onde estão inseridas, devido à natureza de suas atividades. Objetivou-se avaliar a influência de uma intervenção educacional na eficiência de um programa de coleta seletiva já implantado. O resultado mostra que há uma melhoria nos resultados dos questionários e descarte de resíduos recicláveis realizado pela comunidade acadêmica. Logo, foi possível concluir que a intervenção educacional proposta teve impacto positivo na percepção ambiental e na segregação de resíduos recicláveis. Sendo assim, ressalta-se a importância de - PCSS estar associado a programas de Educação Ambiental, com foco contínuo em atividades que estimulem a participação de toda a comunidade acadêmica.

Palavras-chave: Resíduos Sólidos; Reciclagem; Educação Ambiental. 


\section{Introdução}

A geração de resíduos sólidos é inerente à atividade humana e se tornou um dos maiores e mais complexos problemas ambientais da sociedade moderna. $O$ progresso econômico, o desenvolvimento de diversas tipologias industriais, o surgimento de milhares de substâncias sintéticas, as inovações tecnológicas e o incentivo à adoção de padrões de consumo excessivo, com ênfase na produção de materiais descartáveis, têm resultado em uma crescente geração de resíduos sólidos, das mais diversas naturezas, complexidades e características físico-químicas. Todas essas variáveis interrelacionadas tornam o gerenciamento ambientalmente adequado dos resíduos sólidos um desafio, devido à interdependência das etapas de gestão e planejamento adequados.

O processo de integração das etapas de gestão e gerenciamento dos resíduos sólidos é complexo e exige um esforço conjunto de toda a comunidade acadêmica. O Decreto Federal $n^{\circ}$ 5.940/2006 (BRASIL, 2006), que institui a separação dos resíduos recicláveis descartados pelos órgãos da Administração Pública Federal, obriga que os resíduos recicláveis por eles produzidos sejam destinados a associações e cooperativas de catadores legalmente constituídas. Para atingir esse objetivo, a Educação Ambiental é uma ferramenta indispensável para que seja possível construir práticas efetivas em gestão e gerenciamento de resíduos sólidos. Neste contexto, a missão de uma instituição de ensino perpassa pela produção, integração e divulgação do conhecimento, formando cidadãos comprometidos com a ética, a responsabilidade social e o desenvolvimento sustentável. Além disso, tem papel fundamental para efetivar mudanças comportamentais na comunidade onde atua diretamente, por meio das soluções dadas aos seus próprios conflitos e passivos ambientais.

Diante do exposto, é nítida a necessidade de intervenções de caráter educacional junto à comunidade acadêmica, a fim de aumentar a eficiência na recuperação de resíduos recicláveis oriundos da coleta seletiva nas instituições de ensino. Além disso, espera-se que, com o desenvolvimento das ações previstas de sensibilização ambiental, a comunidade acadêmica possa se tornar multiplicadora de práticas sustentáveis, na região na qual está inserida, por meio de seus alunos e servidores.

\section{Objetivos}

Este trabalho foi realizado com o objetivo de avaliar a influência de uma intervenção educacional na eficiência do Programa de Coleta Seletiva Solidária (PCSS) existente no câmpus Barbacena, do Instituto Federal de Educação, Ciência e Tecnologia do Sudeste de Minas Gerais - IFSUDESTE MG. Especificamente, buscou-se: determinar a percepção ambiental dos discentes a respeito da reestruturação do programa de coleta seletiva existente no câmpus, antes e depois das atividades de sensibilização ambiental; avaliar alterações na segregação dos resíduos recicláveis nos coletores externos após

revista brasileira educação ambiental 
a realização de ações de sensibilização ambiental junto à comunidade acadêmica; obter informações que possam subsidiar futuros projetos de Educação Ambiental, a fim de sensibilizar a comunidade acadêmica acerca da importância da segregação dos resíduos sólidos recicláveis e realizar o levantamento de dados que possam auxiliar na elaboração do Plano de Gerenciamento Integrado de Resíduos Sólidos do câmpus Barbacena.

\section{A Educação Ambiental no ambiente escolar}

As universidades e as instituições de ensino podem ser vistas como comunidades com impactos significativos diretos e indiretos no meio ambiente (ALSHUWAIKHAT; ABUBAKAR, 2008). Dessa forma, as instituições têm como premissa fundamental a formação de indivíduos capazes de enfrentar os problemas sociais com um olhar crítico e amplo. Por meio da universalização do conhecimento produzido por elas é que a percepção da problemática ambiental vai se ampliando e promovendo a mudança no comportamental dos cidadãos. Formar pessoas capazes de uma reflexão crítica acerca dos problemas ambientais e sociais que os afetam, preparando-os para exercer a cidadania em sua plenitude, deveria consistir em seu principal objetivo. Os planos de gestão e gerenciamento de resíduos têm ferramentas importantes de sensibilização ambiental, principalmente em ambientes acadêmicos, por sua possibilidade de disseminação na comunidade que os cerca, provocando transformações e mudanças de atitudes.

Assim, a necessidade de elaborar programas de Educação Ambiental, que fazem parte dos planos de gerenciamento dos resíduos, em universidades, deve-se, principalmente, à indispensabilidade de esclarecer e sensibilizar toda a comunidade acadêmica (principalmente alunos, professores e terceirizados) sobre a responsabilidade compartilhada na gestão e no gerenciamento de resíduos sólidos. Dessa forma, a construção de valores e mudanças comportamentais da comunidade acadêmica depende, essencialmente, do processo de sensibilização ambiental.

Para Tavares (2013), as ações diretas dos professores em sala de aula permitem aos educandos uma reflexão e o melhor entendimento dos problemas ambientais que afetam a comunidade onde vivem, pois os educadores são peças fundamentais no processo de conscientização e incentivo a hábitos sadios de conscientização e de conservação ambiental, formando, assim, cidadãos conscientes e comprometidos com o futuro. Dessa forma, a Educação Ambiental deverá proporcionar experiências que possibilitem colocar as pessoas em contato direto com os problemas ambientais, a fim de sensibilizá-las e discutir a importância do ambiente para a saúde, o bem-estar do homem e dos seres vivos e o equilíbrio ambiental dos ecossistemas. Entretanto, Oliveira et al. (2012) ressaltam que é necessário que as abordagens educativas de Educação Ambiental nas escolas sejam um processo continuado, com resultados a longo prazo, pois os resultados são percebidos em um futuro distante. Além disso, recomenda que o processo 
educativo permeie desde a aquisição do conhecimento abstrato até a participação efetiva na construção de tarefas.

Carvalho (2008) preconiza que a Educação Ambiental deve ser abordadanas escolas de modo que não a torne apenas mais uma disciplina na grade curricular, mas um elemento questionador que possa nortear as demais disciplinas, de forma que possam ser repensadas e trabalhadas de forma conjunta e integrada. E que, a partir dos questionamentos gerados, os alunos tenham a capacidade de perceber o papel do ser humano e sua relação com os recursos naturais. No entanto, o autor ressalta que, apesar do relevante papel da Educação Ambiental, ela não é a única estratégia a ser utilizada na luta contra a crise ambiental. Se não for combinada com uma política ambiental efetiva, com uma legislação rígida (que também seja cumprida) ou com ações voltadas para uma distribuição de renda igualitária, dificilmente ocorrerão mudanças efetivas no comportamento das pessoas e na atual situação socioambiental.

De acordo com Karatzoglou (2013), as universidades têm sido conhecidas como importantes colaboradoras na implementação de ações e programas de sustentabilidade. O desenvolvimento de uma Educação Ambiental voltada para os alunos da rede de ensino poderá trazer as bases de uma gestão planejada, integrada e que possa sensibilizar toda a comunidade escolar que futuramente poderá multiplicar a importância da separação dos resíduos sólidos em suas comunidades/bairros, porém, a sua implantação representa o grande desafio, já que depende de investimentos e comprometimento do poder executivo municipal. Dessa forma, a coluna vertebral para a implantação de uma política de coleta seletiva são os programas que reduzem a fonte, recuperam, tratam e dispõem os resíduos sólidos adequadamente.

\section{Material e métodos}

\section{Área de estudo}

A instituição ocupa uma área de aproximadamente 479 hectares, sendo composta por diversas setores, incluindo o setor de laticínios, informática, refeitório, alojamentos, bovinocultura, avicultura, suinocultura, laboratório de química, de solos dentre outros, o que resulta na geração de resíduos extremamente diversificada. Atualmente, o câmpus Barbacena oferece 23 cursos, dentre eles técnicos, tecnológicos, licenciaturas, bacharelados, pósgraduação latu sensu e ensino a distância. Atualmente, a instituição possui 1968 alunos matriculados e aproximadamente 350 servidores (segundo semestre de 2017). Na Figura 1 observa-se a localização geográfica da instituição. 


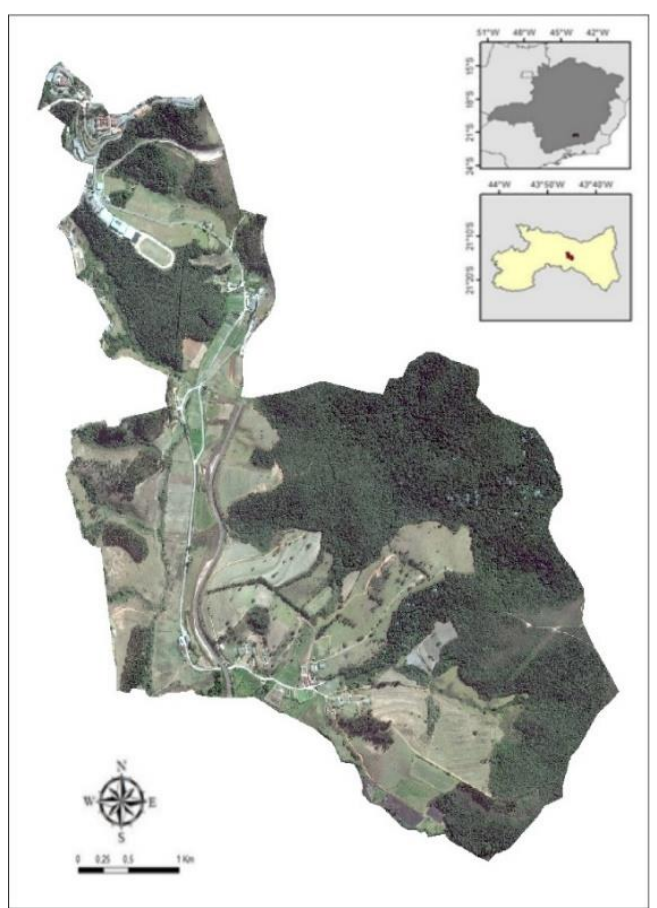

Figura 1: Localização do câmpus Barbacena no município de Barbacena e no estado de Minas Gerais. Fonte: Adaptado de Google Earth Pro, 2018.

Para alcançar os objetivos propostos no presente trabalho, foi realizada uma pesquisa quali-quantitativa exploratória e descritiva, por meio de aplicação de questionário autoaplicado, elaboração de material educativo com intervenção em sala de aula, reunião com colaboradores do sistema de limpeza e coleta de dados em campo. A influência das três etapas de intervenção (Figura 2) foi avaliada por meio da composição gravimétrica nos 33 coletores externos instalados no câmpus Barbacena.

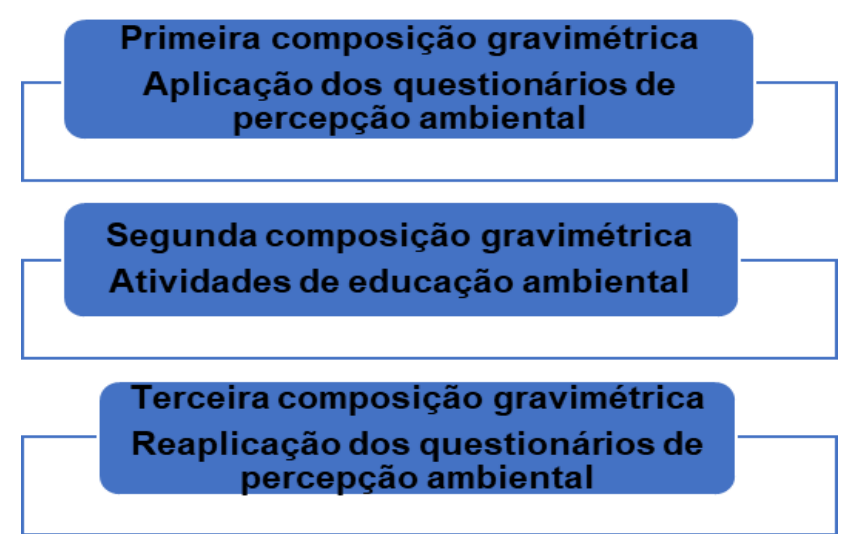

Figura 2: Esquema da metodologia adotada. Fonte: Da autora, 2018.

O objetivo foi o de mensurar a eficiência na segregação dos resíduos recicláveis pela comunidade acadêmica, antes e depois de cada etapa, o que permitiu quantificar a parcela de resíduos segregados corretamente e também Revbea, São Paulo, V. 14, № 1: 456-477, 2019. 
aqueles que são passíveis de serem reciclados. Assim, a gravimetria dos resíduos descartados nos coletores externos foi o principal indicador para analisar a influência da segregação dos resíduos realizada pela comunidade acadêmica, o que permitiu avaliar a interferência de cada etapa de intervenção proposta no presente trabalho.

\section{Atividades de Educação Ambiental}

Para atingir o objetivo de melhorar a eficiência do programa de coleta seletiva existente no câmpus, o PCSS, optou-se por trabalhar com a experiência de vivência, por meio da construção do conhecimento, além das atividades informativas em salas de aula e abordagens para que os alunos e servidores não apenas recebessem o conhecimento "pronto", apenas uma simples transmissão de informação, mas que pudessem construí-lo a partir da informação recebida, sensibilizando-se e conscientizando-se, de forma que mudassem seu comportamento e atitudes. As intervenções educacionais em Educação Ambiental, para serem efetivas, deverão promover 0 desenvolvimento e a apropriação do conhecimento pela comunidade acadêmica. Pretendeu-se proporcionar, nessas atividades, uma reflexão acerca da origem da problemática relacionada aos resíduos sólidos e buscar formas alternativas para solucioná-los.

O material gráfico utilizado foi elaborado em parceria com o Setor de Comunicação Social da instituição. Foram impressos 2.000 folders, 100 cartazes, 29 banners e 50 camisas. Os banners foram instalados nos pontos de maior circulação de pessoas, principalmente nos prédios que concentram maior quantidade de salas de aulas. Durante as atividades, todos os assuntos e conceitos abordados no folder foram discutidos, com apoio de ferramentas digitais (computador e projetor), de forma a evitar a simples panfletagem. Os folders podem ser visualizados na Figura 3.
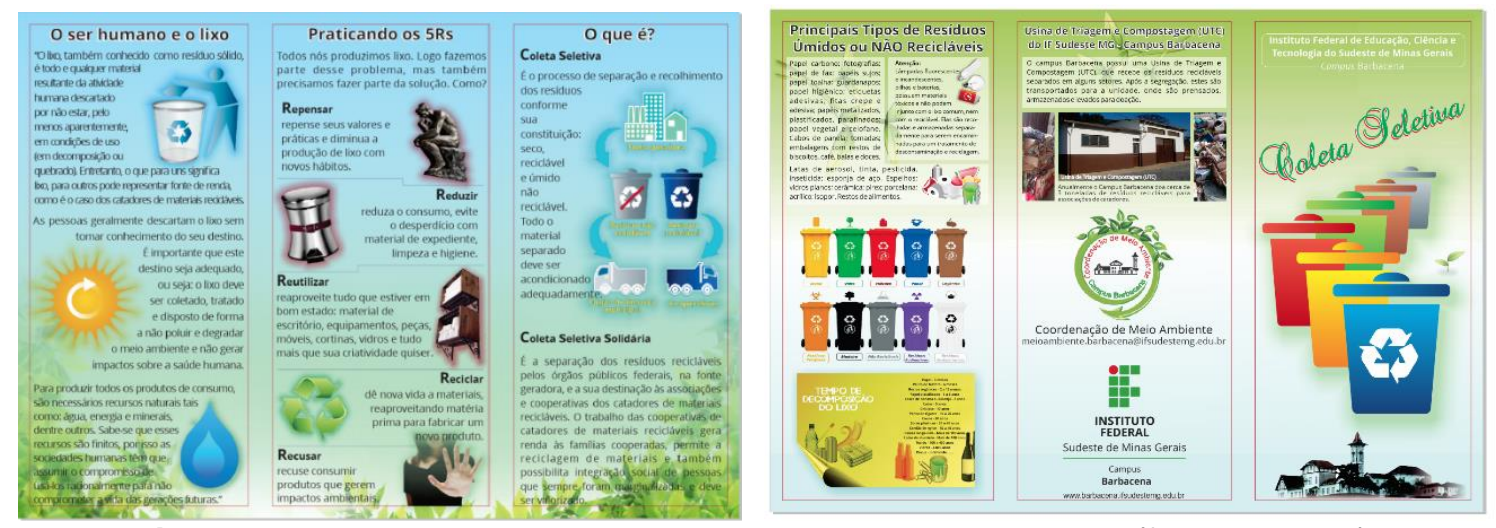

Figura 3: Folder utilizado em atividades de Educação Ambiental (frente e verso).

Fonte: Da autora, 2018. 


\section{Aplicação dos questionários de percepção ambiental}

O questionário de percepção ambiental utilizado nesta pesquisa foi elaborado por Carvalho (2015), em uma análise da coleta seletiva no câmpus da Universidade Federal de Lavras (UFLA) e adaptado para a situação encontrada. As perguntas constantes no questionário abordam questões relacionadas a conceito, conhecimento, participação e disseminação da coleta seletiva no ambiente acadêmico. O questionário foi submetido ao Comitê de Ética em Pesquisa com Seres Vivos da Universidade Federal de Lavras, e aprovado sob o número CAAE 32993214.1.0000.5148.

As entrevistas foram individuais e em sala de aula, após uma explanação rápida acerca dos objetivos da pesquisa e o consentimento prévio dos interessados. Alunos de todos os períodos de todos os cursos foram abordados.

Três estagiários da Coordenação de Meio Ambiente e estudantes do curso de Tecnologia em Gestão Ambiental auxiliaram na aplicação dos questionários (1 ${ }^{a}$ etapa), no período de 16 a 27 de maio de 2016 e também nas composições gravimétricas. A reaplicação do questionário ( $3^{\text {a }}$ etapa) foi realizada entre os dias 3 e 7 de abril de 2017. Para definir o número de amostras optou-se por utilizar a amostragem aleatória estratificada com repartição proporcional, em que a população é dividida em grupos, extraindo-se uma amostra aleatória de cada um deles, de forma proporcional. Optou-se por este tipo de amostragem para que a aplicação dos questionários abordasse de forma proporcional todos os discentes matriculados nos cursos técnicos integrados, subsequentes, tecnólogos e de graduação presenciais existentes. Para o cálculo do tamanho amostral, considerando que a população em estudo é de $\mathrm{N}=1968$ pessoas e um nível de confiança de $95 \%$, o tamanho da amostra (n) deve ser de 561, para uma margem de erro de 3,5\% na estimação da proporção de pessoas com certo comportamento. Para comparar os resultados obtidos nas duas aplicações dos questionários, utilizou-se o teste QuiQuadrado, com nível de 5\% de significância.

\section{Caracterização e composição gravimétrica dos resíduos sólidos}

A composição gravimétrica representa o percentual de cada componente em relação à massa total de resíduos. Os componentes escolhidos para este estudo foram papel, plástico, metal/vidro, matéria orgânica e rejeitos, em função dos compartimentos dos coletores externos instalados no câmpus. O tempo de armazenagem foi de quatro dias, de segunda a sexta-feira (não foram considerados os dias de finais de semana, pois a geração de resíduos diminui muito na instituição), para todas as amostragens, sendo a coleta feita no quinto dia. A primeira caracterização foi feita no mês de março de 2016, a segunda em maio de 2016 e a terceira em março de 2017. Os resíduos foram segregados por tipologia (papel, plástico, vidro/metal, matéria orgânica e rejeitos não recicláveis, e materiais de difícil classificação). As três 
variáveis analisadas neste estudo foram: resíduos descartados corretamente (RDC): porcentagem (em peso) dos resíduos descartados em compartimento correto, respectivo a sua tipologia; resíduos descartados incorretamente (RDI): porcentagem (em peso) dos resíduos descartados em compartimento incorreto, ou seja, não respectivo a sua tipologia e resíduos potencialmente recicláveis (RPR): resíduos recicláveis (papel, plástico, metal ou vidro) descartados nos coletores, independente do compartimento, que estejam em condições de serem reaproveitados, reutilizados ou reciclados.

\section{Resultados e discussão}

Verificou-se que, conforme pode ser observado no Gráfico 1, que as médias das porcentagens em peso calculadas para todos os coletores analisados, relativos às variáveis RDC e RPR aumentaram ao longo do desenvolvimento do projeto, contrapondo inversamente a variável RDI (resíduos descartados incorretamente). Contudo, após as intervenções educacionais em salas de aula, houve uma melhora significativa na segregação de resíduos recicláveis (aumento de 19,63\%), demonstrada pela variável RDC. Já a variável RPR também apresentou uma variação positiva (aumento de $11,81 \%)$, pois o potencial de reciclagem de um resíduo reciclável está diretamente associado a forma como é acondicionado na fonte geradora.

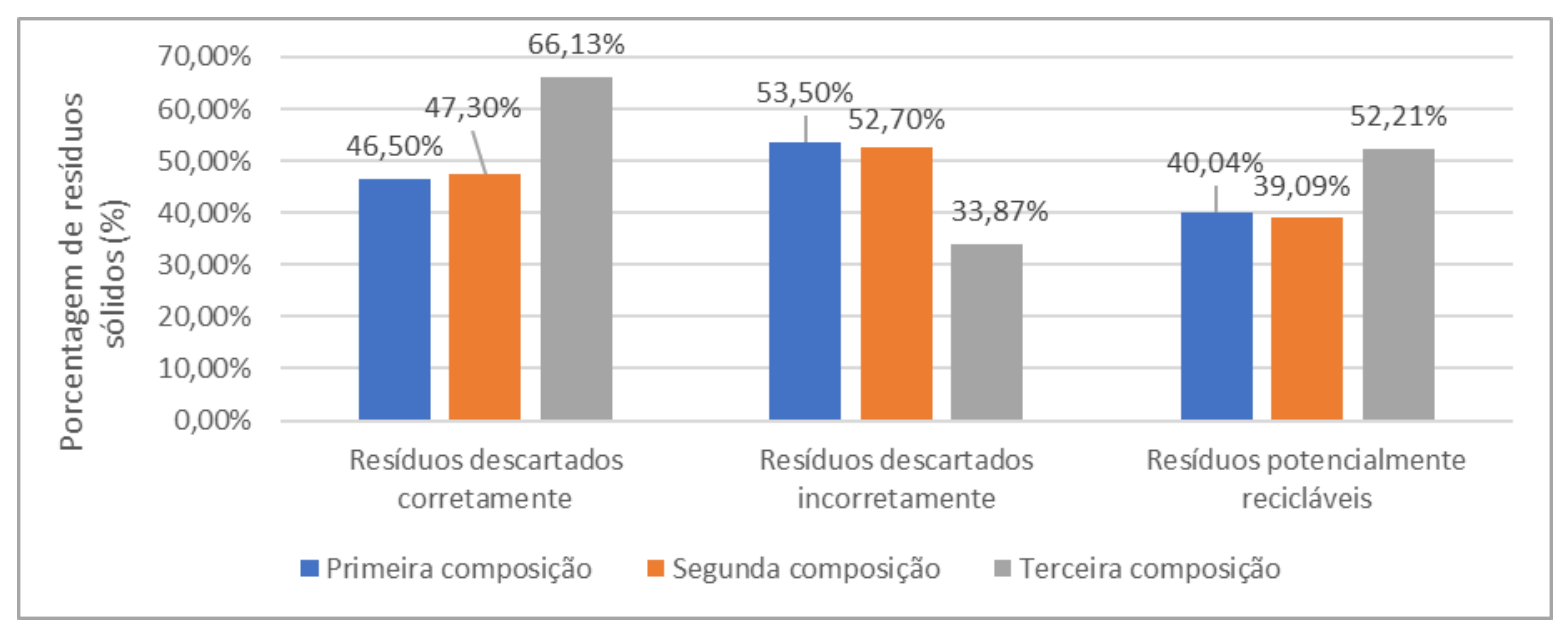

Gráfico 1: Médias das porcentagens das variáveis RDC, RDI e RPR, durante as três composições gravimétricas. Fonte: Da autora, 2017.

O Gráfico 2 apresenta o resultado de dispersão dos dados de RDC2 e RDC3, em que foi obtido um coeficiente de correlação de 0,4110. Segundo a classificação adotada (MUKAKA, 2012), o valor encontrado indica intensidade moderada da relação linear entre as duas variáveis. 


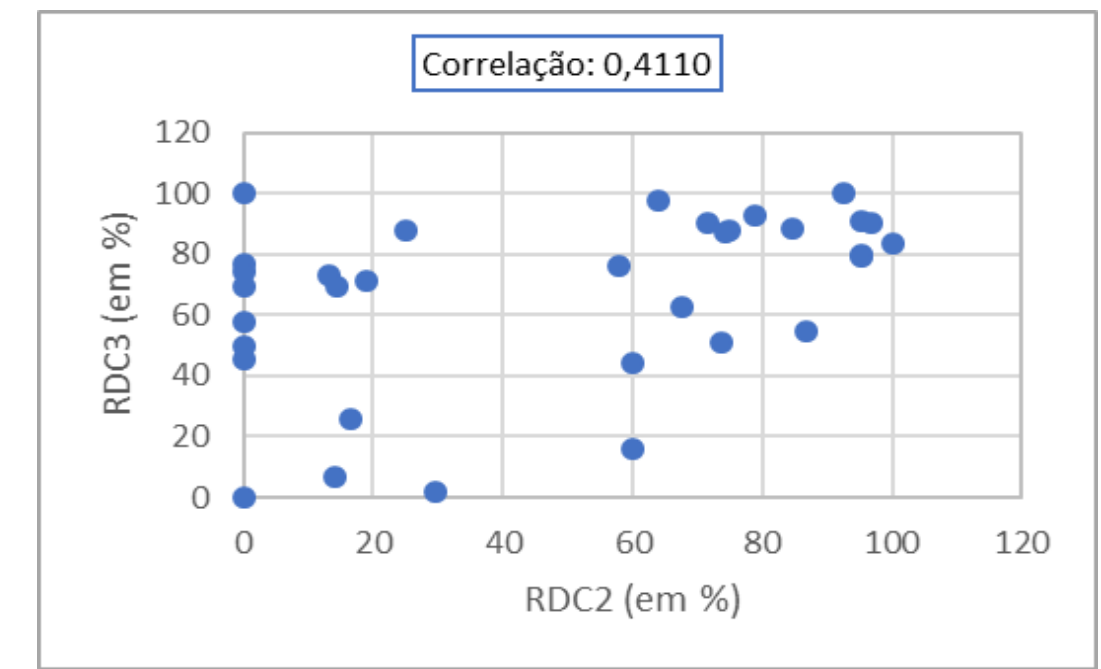

Gráfico 2: Dispersão da variável RDC2 e RDC3. Fonte: Da autora, 2017.

Legenda:

RDC2 - Resíduos descartados corretamente na segunda composição gravimétrica RDC3 - Resíduos descartados corretamente na terceira composição gravimétrica

Para a pergunta 3, que abordou se o discente já havia participado de alguma palestra ou atividade sobre meio ambiente no câmpus, antes das intervenções em sala, foram obtidas 671 respostas, segundo as quais 219 $(32,64 \%)$ entrevistados relataram nunca terem participado e $452(67,36 \%)$ já terem participado. Após as intervenções, foram obtidas 688 respostas, sendo $279(40,55 \%)$ positivas e 409 (59,45\%) negativas. Os resultados comparativos apresentaram diferença estatisticamente significativa $(p=0,002)$, evidenciando que os alunos reconheceram a participação nas atividades educacionais propostas por este estudo.

Para a pergunta 5, que indagava sobre o conhecimento do discente sobre o conceito de coleta seletiva, antes das intervenções em sala, foram obtidas 673 respostas. Desse total $448(66,57 \%)$ diziam saber o que é coleta seletiva (questão 5), 27 (4,01\%) não sabiam e 198 (29,42\%) já tinham ouvido falar, mas não sabiam o que significava exatamente o termo. Após as atividades de Educação Ambiental em sala, foram obtidas 687 respostas, das quais $521(75,84 \%)$ eram de que tinham conhecimento, apenas $20(2,91 \%)$ não sabiam e $146(21,25 \%)$ já tinham ouvido falar. Os resultados comparativos apresentaram diferença estatisticamente significativa $(p=0,001)$, evidenciando que as atividades educacionais foram eficientes para elucidar acerca dos conceitos propostos na questão. Carvalho (2015) encontrou um resultado bem superior ao deste estudo, pois $89,6 \%$ dos entrevistados relataram saber o que era coleta seletiva, enquanto $9,7 \%$ já tinham ouvido falar e apenas $0,7 \%$ não sabiam. Essa diferença pode estar relacionada ao público-alvo ao qual o questionário foi aplicado, composto exclusivamente por universitários, dos quais se espera um conhecimento maior sobre as questões ambientais. Para a 
mesma questão, a porcentagem de discentes que acreditam na importância e na necessidade da coleta seletiva passou de 61,83\% para 73,09\%.

Em um estudo realizado em 10 universidades e institutos de tecnologia na China, Zhang (2017) identificou relação positiva e significativa entre as atividades de conscientização e campanhas relacionadas à separação de resíduos sólidos e alterações em seus comportamentos. O autor ressalta que o conhecimento acerca dos impactos ambientais negativos causados pelo gerenciamento inadequado também ajuda os alunos a terem um melhor entendimento sobre a importância de seus esforços. Contudo, Queiroz e Pedrini (2014) relatam que, mesmo que os indivíduos estejam cientes do conceito de coleta seletiva, eles podem não compreender todos os fatores envolvidos, além da sua pertinência e necessidade. Sendo assim, poderá comprometer a eficiência de um programa de coleta seletiva a longo prazo. Neves e Castro (2012) afirmam que $86 \%$ da população brasileira concordam que a separação de materiais recicláveis é um dever de todos, porém, apenas $26 \%$ declararam que separam os materiais sempre ou frequentemente.

Em relação aos conceitos de reaproveitamento e reciclagem (questão 6), antes das atividades em sala, considerando um total de 672 respostas, 395 entrevistados $(58,78 \%)$ relataram saber diferenciar, 77 (11,46\%) não sabiam e $200(29,76 \%)$ relataram não ter certeza. Ao reaplicar o questionário, do total de 684 respostas, 357 discentes $(52,19 \%)$ relataram saber diferenciar os conceitos, $85(12,43 \%)$ não sabiam e 242 (35,38\%) informaram não ter certeza. $O$ resultado do teste estatístico indicou diferença significativa $(p=0,045)$, evidenciando que as atividades educacionais não foram eficientes para elucidar acerca da diferença entre os dois conceitos, pois a porcentagem de alunos que sabiam diferenciar diminuiu e a daqueles que não tinham certeza aumentou. Todavia, a porcentagem encontrada após as atividades educacionais se aproxima dos valores encontrados por Carvalho (2015), que identificou, em seu estudo, que 52,8\% dos universitários não sabiam diferenciar esses conceitos. Soares, Pereira e Cândido (2017), em um estudo sobre a percepção ambiental dos discentes da Universidade Estadual da Paraíba (UEPB) relataram que 84,3\% dos entrevistados apresentaram de forma correta a definição de reciclagem. Os autores concluíram que este resultado pode estar associado à existência do programa de coleta seletiva municipal, que contribuiu para o conhecimento acerca do assunto. A PNRS define reciclagem como "um processo de transformação dos resíduos que envolve a alteração de suas propriedades físicas, físico-químicas ou biológicas, com vistas à transformação em insumos ou novos produtos", enquanto na reutilização não há transformações destas propriedades.

Para a questão 7, que abordou sobre a existência de separação de resíduos sólidos no câmpus Barbacena, dentre as 677 repostas obtidas antes das atividades em sala, $208(30,72 \%)$ afirmaram conhecer a existência do projeto e 469 (69,28\%) disseram não conhecer. No estudo conduzido por Soares, Pereira e Cândido (2017), a porcentagem de entrevistados que desconheciam a destinação final dos resíduos gerados na UEPB foi bem 
superior $(81,25 \%)$. Após as atividades, de 687 respostas obtidas, 425 discentes $(61,86 \%)$ informaram ter conhecimento e $262(38,14 \%)$ não ter conhecimento. $O$ resultado do teste estatístico apresentou diferença significativa $(p=0,000)$, evidenciando que as atividades educacionais foram eficientes para informar sobre a existência do projeto de coleta seletiva solidária. Carvalho (2015) encontrou $63 \%$ de respostas positivas, em seu estudo na Universidade Federal de Lavras (UFLA).

Em relação ao destino dado aos resíduos sólidos gerados no câmpus Barbacena (questão 8), antes das intervenções, considerando um total de 670 respostas, 17 discentes disseram que eles são encaminhados para o lixão (2,54\%), 25 (3,73\%) indicaram como destino o aterro sanitário, 7 (1,04\%) mencionaram aterro controlado e $7(1,04 \%)$ responderam a associação de catadores; 611 (91,19\%) não sabiam e $3(0,45 \%)$ relataram outras respostas. Estes resultados estão próximos dos encontrados por Carvalho (2015), que identificou que $88 \%$ dos estudantes da UFLA não sabiam qual a destinação dada aos resíduos produzidos na instituição. Na reaplicação do questionário, das 687 respostas obtidas, $10(1,46 \%)$ assinalaram lixão, $16(2,33 \%)$ aterro sanitário, $4(0,58 \%)$ aterro controlado, $178(25,91 \%)$ associação de catadores, $477(69,43 \%)$ não sabiam e $2(0,29 \%)$ deram outras respostas. O resultado do teste estatístico comprovou diferença significativa $(p=0,000)$, evidenciando que as atividades educacionais foram eficientes para informar acerca da destinação dos resíduos sólidos produzidos na instituição.

$\mathrm{Na}$ questão 10, que abordou a correspondência entre as cores dos compartimentos dos coletores e as tipologias dos resíduos, antes das intervenções, do total de 666 respostas, 137 entrevistados (20,57\%) relataram saber todas as cores, $263(39,49 \%)$ disseram não saber e 266 (39,94\%) sabiam apenas algumas cores. Neste quesito, Soares, Pereira e Cândido (2017) também descreveram a necessidade de campanhas informativas e de Educação Ambiental que sejam capazes de elucidar a as dúvidas existentes quanto aos diferentes tipos de materiais que podem ser reutilizados. Depois, considerando um total de 685 respostas, 188 discentes $(27,45 \%)$ disseram saber identificar todas as cores, 179 (26,13\%) não sabiam e 318 (46,42\%) sabiam apenas algumas cores. Os resultados comparativos apresentaram diferença estatisticamente significativa $(p=0,00)$, evidenciando que as atividades educacionais foram eficientes para esclarecer acerca do significado das cores em relação à tipologia de resíduos que a mesma representa. Com relação aos entrevistados que acertaram todas as cores, os valores encontrados após as atividades educacionais se assemelham aos apontados por Carvalho (2015), bem como foi possível tabular a quantidade de acertos e também apresentar, com mais exatidão, quais tipologias obtiveram maior êxito. $\mathrm{Na}$ Tabela 1 apresenta-se a quantidade de acertos obtidos, antes e depois das atividades de Educação Ambiental. 
Tabela 1: Respostas para a questão 10.1 Você conhece algumas ou todas, e quais cores você sabe o material correspondente?

\begin{tabular}{lcc}
\hline & Antes & Depois \\
\hline Acertou 1 cor & $45(11,17 \%)$ & $22(4,35 \%)$ \\
Acertou 2 cores & $93(23,08 \%)$ & $89(17,59 \%)$ \\
Acertou 3 cores & $64(15,88 \%)$ & $122(24,11 \%)$ \\
Acertou 4 cores & $39(9,68 \%)$ & $95(18,77 \%)$ \\
Acertou 5 cores & $30(7,44 \%)$ & $69(13,64 \%)$ \\
Fora de contexto & $15(3,72 \%)$ & $0(0,00 \%)$ \\
Não & $117(29,03 \%)$ & $110(21,74 \%)$ \\
\hline \multicolumn{2}{c}{ Total } & 403 \\
\hline
\end{tabular}

Foi testado também se existe diferença entre o número de acertos, de acordo com a cor e a tipologia dos resíduos, antes e depois da intervenção. $\mathrm{Na}$ Tabela 2 apresenta-se a quantidade de acertos obtidos, antes e depois das atividades de Educação Ambiental, por tipologia de resíduos.

Tabela 2: Acertos na questão 10.1, de acordo com a cor e a tipologia do compartimento do

\begin{tabular}{lccc}
\multicolumn{4}{c}{ coletor. } \\
\hline Antes & Depois & Valor-p \\
\hline Papel & $243(61,06 \%)$ & $403(72,05 \%)$ & $0,000^{*}$ \\
Plástico & $242(60,80 \%)$ & $362(71,26 \%)$ & $0,001^{*}$ \\
Metal-vidro & $148(37,19 \%)$ & $249(49,02 \%)$ & $0,000^{*}$ \\
Matéria Orgânica & $107(26,88 \%)$ & $195(38,39 \%)$ & $0,000^{*}$ \\
Não reciclável & $33(8,29 \%)$ & $78(15,35 \%)$ & $0,001^{*}$ \\
\hline
\end{tabular}

Legenda:

Fonte: Da autora, (2018).

*Significância estatística

Todos os testes concluíram que houve diferença significativa no número de acertos, para todas as tipologias de resíduos (valor de $p<0,05$ ), ou seja, as atividades presenciais foram efetivas para fixar o conhecimento acerca da correspondência cor-tipologia para todos os compartimentos utilizados na instituição.

Com relação às dificuldades encontradas pelos discentes acerca da correta segregação dos resíduos sólidos (questão 11), descritas na Tabela 3 , os principais argumentos relatados foram falta de incentivo $(p=0,004$, de $59,26 \%$ para $51,46 \%$ ); não saber onde depositar o resíduo, mesmo sabendo o que é reciclável ou não ( $p=0,000$, de $44,59 \%$ para $31,63 \%)$; poucos locais de coleta ( $p=0,000$, de $59,85 \%$ para $40,38 \%$ ) e falta de sinalização dos coletores ( $p=0,000$, de $21,33 \%$ para $13,70 \%$ ). Todavia, esses apontamentos feitos pelos discentes apresentaram uma porcentagem decrescente, demonstrando que as dificuldades apresentadas durante a primeira aplicação do questionário apresentaram uma evolução positiva após o início das atividades deste projeto. 
Tabela 3: Resposta para a questão 11 " Na sua opinião, quais as dificuldades encontradas na separação de resíduos recicláveis?

\begin{tabular}{lccr}
\hline & Antes & Depois & Valor-p \\
\hline Pouco conhecimento & $351(52,00 \%)$ & $366(53,35 \%)$ & 0,617 \\
Pouca comunicação & $191(28,30 \%)$ & $209(30,47 \%)$ & 0,076 \\
$\begin{array}{l}\text { Falta de incentivo } \\
\text { Pouco interesse das pessoas }\end{array}$ & $400(59,26 \%)$ & $353(51,46 \%)$ & $0,004^{*}$ \\
pela temática ambiental & $451(66,81 \%)$ & $485(70,70 \%)$ & 0,122 \\
$\begin{array}{l}\text { Não reconhecer o que é } \\
\text { reciclável }\end{array}$ & $190(28,15 \%)$ & $203(29,59 \%)$ & 0,557 \\
$\begin{array}{l}\text { Não saber onde depositar, } \\
\text { mesmo sabendo que é }\end{array}$ & $301(44,59 \%)$ & $217(31,63 \%)$ & $0,000^{*}$ \\
reciclável & & & \\
$\begin{array}{l}\text { Poucos locais de coleta } \\
\text { Falta de sinalização dos }\end{array}$ & $404(59,85 \%)$ & $277(40,38 \%)$ & $0,000^{*}$ \\
$\begin{array}{l}\text { coletores } \\
\text { Não sei }\end{array}$ & $144(21,33 \%)$ & $94(13,70 \%)$ & $0,000^{*}$ \\
Outros & $23(3,41 \%)$ & $8(1,17 \%)$ & 0,006 \\
& $42(6,22 \%)$ & $38(5,54 \%)$ & 0,592 \\
& & & \\
\hline
\end{tabular}

Legenda:

Fonte: Da autora, (2018).

*Significância estatística

As principais dificuldades relatadas pelos alunos da instituição para a efetivação da coleta seletiva se assemelham aos entraves descritos no trabalho de Carvalho (2015), no qual $87 \%$ dos entrevistados citaram o pouco interesse pela temática ambiental, $62 \%$ mencionaram a falta de incentivo, $54 \%$ relataram o pouco conhecimento e 53\%, a falta de comunicação. Considerações coincidentes foram feitas por Zago et al. (2014), que alertaram sobre o descaso de grande parte dos servidores administrativos do Centro Federal de Educação Tecnológica de Minas Gerais e advertiram sobre o risco de os resíduos recicláveis previamente separados serem novamente misturados, tendo, assim, a mesma destinação do lixo comum. Em um estudo sobre a participação da população em programas de coleta seletiva, Bringhenti e Gunther (2011) concluíram que a falta de divulgação dos resultados, a acomodação e o desinteresse da população, o descrédito relativo às ações oriundas do poder público e a falta de espaço nas residências para armazenar os resíduos recicláveis são fatores que dificultam a participação em programas municipais. Diaz-Rocha e Massambani (2008) apontaram que um dos maiores problemas enfrentados pelo projeto USP Recicla é o descaso dos administradores daquela instituição de ensino.

Sobre a pergunta 12, que questionava a preferência dos discentes por coletores compartimentalizados de acordo com o material (como os coletores externos já instalados) em comparação aqueles com apenas dois compartimentos (recicláveis e não recicláveis), foi obtido valor de $p=0,015$. Antes da intervenção, 192 discentes (32,54\%) preferiam coletores com apenas dois compartimentos e, após a reaplicação dos questionários, essa porcentagem aumentou para 39,27\% (227 respostas). No entanto, a porcentagem de alunos que preferiam os coletores externos com cinco Revbea, São Paulo, V. 14, № 1: 456-477, 2019. 
compartimentos diminuiu de 67,46\% (398 respostas) para 60,55\% (398 respostas). Em relação aos motivos alegados pela preferência aos coletores separados em cinco compartimentos, após as intervenções, $62 \%$ dos alunos relataram ser mais fácil e $13,71 \%$ disseram que melhora a separação (350 entrevistados). Carvalho (2015), nesse quesito, apurou porcentagens quase equivalentes, tendo $46,4 \%$ dos entrevistados revelado preferir a coleta por componente (de acordo com o material) e 42,38\%, em apenas dois compartimentos (reciclável e não reciclável).

Em relação ao que pode ser feito para a retomada da coleta seletiva na instituição (questão 13), conforme Tabela 4, as alternativas mais escolhidas pelos discentes, antes e depois das intervenções em sala foram as seguintes: mapa do câmpus com localização dos coletores $(p=0,000)$; informação no site da instituição $(p=0,038)$; envio de e-mails $(p=0,008)$; panfletos impressos $(p=0,025)$; palestras, eventos e minicursos $(p=0,038)$; placas informativas pelo câmpus $(p=0,000)$ e atividades em sala de aula $(p=0,002)$. Dentre as opções mais destacadas pelos alunos, com exceção do envio dos e-mails, todas as sugestões elencadas por eles foram realizadas durante a etapa de sensibilização ambiental. $O$ envio de e-mails não foi possível devido à falta desta informação no cadastro dos alunos nas secretarias acadêmicas (de graduação, ensino médio e técnico). Neves e Castro (2012) ressaltam que a participação das pessoas é fundamental para o sucesso de qualquer programa de coleta seletiva e que o entendimento dos fatores que motivam e desmotivam as pessoas a realizar a separação de material reciclável em determinado local é crucial para o sucesso do programa.

Tabela 4: Resposta para a questão 13: Para você, o que pode ser feito para que a retomada da coleta seletiva no câmpus Barbacena realmente funcione?

\begin{tabular}{lccl}
\hline & Antes & Depois & Valor-p \\
\hline Mapa do câmpus com a & & & \\
localização dos coletores & $278(41,12 \%)$ & $180(27,36 \%)$ & $0,000^{*}$ \\
Informação no site do câmpus & $218(32,25 \%)$ & $178(27,05 \%)$ & $0,038^{*}$ \\
Envio de e-mails & $56(8,28 \%)$ & $31(4,71 \%)$ & $0,008^{*}$ \\
Panfletos impressos & $166(24,56 \%)$ & $128(19,45 \%)$ & $0,025^{*}$ \\
Palestras, eventos e minicursos & $331(48,96 \%)$ & $285(43,31 \%)$ & $0,038^{*}$ \\
Placas informativas pelo câmpus & $402(59,47 \%)$ & $322(48,94 \%)$ & $0,000^{*}$ \\
Cartazes com instruções nas & & & \\
cantinas e salas de aula & $323(47,78 \%)$ & $240(36,47 \%)$ & 0,094 \\
Atividades em sala & $155(22,93 \%)$ & $158(24,01 \%)$ & $0,002^{*}$ \\
Não sei & $48(7,10 \%)$ & $50(7,40 \%)$ & 0,727 \\
Outro & $40(5,92 \%)$ & $22(3,34 \%)$ & $0,026^{*}$ \\
\hline
\end{tabular}

Fonte: Da autora, (2018).

Legenda:

*Significância estatística

A questão 14 questionou sobre a quem compete a responsabilidade de motivar e orientar a comunidade acadêmica acerca da retomada do programa de coleta seletiva solidária, e os alunos poderiam marcar mais de uma opção (Tabela 5). Antes das atividades em sala, 494 respostas $(76,71 \%)$ foram de 
que esta iniciativa deveria partir da coordenação de meio ambiente do câmpus; para 301 alunos $(46,74 \%)$, esta ação deveria também partir dos professores, para 240 alunos (37,27\%), bem como da direção; para 239 alunos $(37,11 \%)$ a associação de catadores igualmente tem essa reponsabilidade; 186 alunos $(28,88 \%)$ citaram os servidores técnico-administrativos e 160 alunos $(24,84 \%)$ mencionaram os chefes de departamento. Com relação aos setores ligados diretamente aos discentes, para 182 alunos (28,26\%), os centros acadêmicos deveriam ter essa incumbência e 116 alunos (18,01\%) mencionaram o diretório central dos estudantes (DCE). Ao comparar os resultados obtidos com aqueles apresentados por Carvalho (2015), verifica-se também uma correspondência semelhante na questão. A autora identificou que os alunos da UFLA atribuem a responsabilidade pela orientação e motivação, principalmente, à Diretoria de Meio Ambiente (91\%), aos centros acadêmicos (56\%) e aos professores $(46 \%)$.

Tabela 5: Resposta para questão 14 "Na sua opinião, esta orientação e motivação para a retomada da coleta seletiva no câmpus Barbacena têm que ser feitas por quem?

\begin{tabular}{lccc}
\hline & Antes & Depois & Valor-p \\
\hline Professores & $301(46,74 \%)$ & $327(49,77 \%)$ & 0,286 \\
Técnico-administrativos & $186(28,88 \%)$ & $135(20,55 \%)$ & $0,000^{*}$ \\
& $239(37,11 \%)$ & $198(30,14 \%)$ & $0,007^{*}$ \\
Associação de catadores parceira & & & \\
Coordenação de meio ambiente & $494(76,71 \%)$ & $516(78,54 \%)$ & 0,459 \\
Coordenadores dos cursos & $220(34,16 \%)$ & $209(31,81 \%)$ & 0,357 \\
Chefes de departamento & $160(24,84 \%)$ & $99(15,07 \%)$ & $0,000^{*}$ \\
Diretores & $240(37,27 \%)$ & $194(29,53 \%)$ & $0,003^{*}$ \\
Centros acadêmicos & $182(28,26 \%)$ & $151(22,98 \%)$ & $0,028^{*}$ \\
Diretório Central dos Estudantes & $116(18,01 \%)$ & $90(13,70 \%)$ & $0,032^{*}$ \\
Não sei & $45(6,99 \%)$ & $35(5,33 \%)$ & 0,210 \\
Outro & $42(6,52 \%)$ & $26(3,96 \%)$ & $0,037^{*}$ \\
\hline
\end{tabular}

Fonte: Da autora, (2018).

Legenda:

*Significância estatística

$\mathrm{Na}$ questão 15 perguntou-se se os discentes conheciam alguma associação de catadores de materiais recicláveis. Do total de 647 respostas obtidas antes das intervenções, 506 alunos $(78,21 \%)$ relataram não conhecer, $94(14,53 \%)$ já tinham ouvido falar e apenas $47(7,26 \%)$ afirmaram conhecer. Após as atividades, para o mesmo número de respostas, $438(68,22 \%)$ assinalaram não conhecer, 147 (22,90\%) já tinham ouvido falar e 57 (8,8\%) relataram conhecer. Para Carvalho (2015), a porcentagem de entrevistados que conheciam a associação de catadores parceira da UFLA, a ACAMAR, foi de $58,4 \%$, percentual que pode ser atribuído ao trabalho que ela executa no município de Lavras, tornando-a mais conhecida.

Os resultados comparativos apresentaram diferença estatisticamente significativa $(p=0,00)$, evidenciando que as atividades educacionais conseguiram apresentar aos discentes a parceria existente entre a ASCAB e a instituição, já que no município de Barbacena não existe uma associação de catadores legalmente constituída. Esta questão também questionava qual Revbea, São Paulo, V. 14, № 1: 456-477, 2019. 
associação o discente conhecia. Das 57 respostas positivas, após as atividades, 12 discentes (21,05\%) disseram conhecer a ASCAB e 21 (36,84\%), a associação de catadores do município de Bertioga. A associação trabalha dentro da UTC do município, vizinho a Barbacena, sendo um local onde os professores da área ambiental normalmente fazem visitas técnicas.

Considerando a percepção dos alunos acerca do trabalho realizado pelos "catadores de materiais recicláveis" (questão 17), na qual eles poderiam marcar mais de uma opção, após as atividades em sala, para 447 deles (88,34\%) este trabalho é importante, útil e necessário; 16 alunos (3,16\%) relataram a importância do trabalho do catador para a preservação ambiental; entretanto, $13(2,57 \%)$ relataram o pouco reconhecimento social, $10(1,98 \%)$ ressaltaram a insalubridade e a periculosidade envolvida e 9 a $(1,78 \%)$ disseram que não conhecem essa atividade ou não souberam responder.

A questão 18 abordou o conhecimento dos discentes acerca da rotina desses trabalhadores (catadores de materiais recicláveis). Para 649 respostas obtidas antes das atividades, 560 alunos (86,29\%) relataram não conhecer, 69 $(10,63 \%)$ disseram conhecer um pouco e $20 \quad(3,08 \%)$ afirmaram ter conhecimento. Após as atividades, para 656 respostas, 522 discentes $(79,57 \%)$ assinalaram não conhecer, 111 (16,92\%) responderam conhecer um pouco e $23(3,51 \%)$ disseram que conheciam. Os resultados comparativos apresentaram diferença estatisticamente significativa $(p=0,004)$, evidenciando que as atividades educacionais foram eficientes para mostrar um pouco da rotina e as dificuldades encontradas por estes trabalhadores. Dentre as opiniões relatadas, antes e depois das atividades, as questões mais abordadas foram trabalho difícil, cansativo, pesado, árduo e desvalorizado. Carvalho (2015) também identificou um percentual aproximado, tendo $85 \%$ dos entrevistados revelado que não tinham conhecimento sobre a rotina de um catador de materiais recicláveis.

Sobre a participação dos alunos no PCSS (questão 20), para 645 respostas obtidas, 299 (46,36\%) afirmaram participar do programa, 194 $(30,08 \%)$ participam às vezes e $123(19,07 \%)$ não participam. Após as atividades, para 653 respostas, 262 alunos $(40,12 \%)$ participariam, 108 (16,54\%) não participariam e 250 (38,28\%) participariam eventualmente. Carvalho (2015) também identificou um percentual aproximado de alunos que participam da coleta seletiva na UFLA (46,5\%). Os resultados comparativos apresentaram diferença estatisticamente significativa $(p=0,014)$, que representa uma maior disposição dos discentes em participarem do PCSS. Antagonicamente ao resultado encontrado na questão 19, que indagou sobre a mesma questão para o município de Barbacena, o teste não obteve correlação estatisticamente significativa $(p=0,088)$. O município de Barbacena não possui um PCS e não conta com uma política pública bem definida com relação aos resíduos sólidos, de forma que é possível inferir que, quando há incentivo e investimento em programas desse tipo, a população tende a responder positivamente. 
Sobre a forma como os alunos gostariam de ser orientados sobre como proceder na segregação correta dos resíduos sólidos (questão 21), os resultados estão descritos na Tabela 6. Antes das intervenções, 302 alunos citaram eventos e minicursos (46,60\%), 300 alunos mencionaram cartazes informativos (46,30\%), 292 alunos indicaram abordagem em salas de aula $(45,06 \%), 261$ alunos $(40,28 \%)$ apontaram a distribuição de panfletos educativos, 235 alunos $(36,27 \%)$ mencionaram a realização de visitas técnicas e, para 195 alunos $(30,09 \%)$, seria muito importante a presença dos catadores na instituição. Após as intervenções em sala, a maioria dos alunos passou a optar por atividades em sala. Nesta questão, os alunos poderiam optar por mais de uma resposta.

Tabela 6: Resposta para a questão 21: Como você gostaria de ser orientado sobre como proceder em relação à coleta seletiva no câmpus Barbacena?

\begin{tabular}{lccc}
\hline & Antes & Depois & Valor-p \\
\hline Panfletos educativos & $261(40,28 \%)$ & $231(35,11 \%)$ & $0,060^{*}$ \\
Cartazes informativos & $300(46,30 \%)$ & $267(40,58 \%)$ & $0,042^{*}$ \\
Abordagem em sala de aula & $292(45,06 \%)$ & $293(44,53 \%)$ & 0,886 \\
Eventos e minicursos & $302(46,60 \%)$ & $284(43,16 \%)$ & 0,230 \\
Presença de catadores de materiais & $195(30,09 \%)$ & $173(26,29 \%)$ & 0,136 \\
recicláveis & & & \\
Visitas técnicas & $235(36,27 \%)$ & $250(37,99 \%)$ & 0,491 \\
Não preciso de orientação & $24(3,70 \%)$ & $19(2,89 \%)$ & 0,414 \\
Não sei & $42(6,48 \%)$ & $26(3,95 \%)$ & $0,041^{*}$ \\
Outro & $8(1,23 \%)$ & $6(0,91 \%)$ & $0,037^{*}$ \\
\hline
\end{tabular}

Fonte: Da autora, (2018).

Legenda:

*Significância estatística

A questão 23 indagou os entrevistados sobre a localização dos coletores dentro da instituição. Antes das atividades em sala, 332 alunos $(51,23 \%)$ sabiam onde eles se encontravam, 252 alunos (38,89\%) relataram conhecer onde ficam apenas alguns e 64 alunos $(9,88 \%)$ não sabiam. Após as atividades em sala, 382 alunos (58,59\%) afirmaram saber onde ficam alguns coletores, 171 alunos (26,23\%) relataram saber e 99 alunos (15,18\%) não sabiam. 0 resultado do teste estatístico apresentou diferença significativa $(p=0,000)$, evidenciando que as atividades educacionais foram eficientes para esclarecer os discentes acerca da localização dos coletores a, pois esta informação estava presente no folder distribuído, nos banners e no material digital apresentado em sala. A proximidade dos coletores de resíduos sólidos tem grande influência sobre o comportamento da comunidade, pois incentiva as pessoas a separarem adequadamente (MALAKAHMAD, 2010). Segundo Lansana (1992), quanto menor a distância, maior será a probabilidade de as pessoas separarem seus resíduos. Nithya (2012), em um estudo utilizando um Sistema de Informação Geográfica (SIG) para investigar a distância a pé ideal para a localização dos coletores, de forma a contribuir para a correta destinação dos resíduos sólidos e encaminhamento ao sistema de coleta Revbea, São Paulo, V. 14, № 1: 456-477, 2019. 
municipal, constatou que a distância ótima é de 75 metros. Segundo este autor, a distância ideal encontra-se entre 100 a 500 metros.

Do ponto de vista dos alunos, as informações e as orientações sobre a coleta seletiva durante os primeiros dias dos alunos no câmpus Barbacena melhorariam esta prática (questão 24). Antes das atividades, para 646 respostas, 369 alunos $(57,12 \%)$ acreditam que sim, 34 (5,36\%) que não e 243 $(37,62 \%)$ relataram que talvez possam ajudar. Após as atividades, 370 alunos $(56,23 \%)$ responderam que essa informação pode ajudar e 269 (40,88\%) acreditam que talvez esta intervenção possa funcionar. Os resultados comparativos apresentaram diferença estatisticamente significativa $(p=0,046)$, mostrando que, de acordo com o ponto de vista dos discentes, as atividades de Educação Ambiental deveriam acontecer desde o início do ingresso deles na instituição. Essa opinião também vai ao encontro do desejado pelos alunos da UFLA, pois $95 \%$ dos entrevistados responderam que essa prática melhoraria os resultados (CARVALHO, 2015).

Sobre o conhecimento da existência da Política Nacional de Resíduos Sólidos (questão 25), antes das intervenções em sala, 477 alunos (73,95\%) disseram não ter conhecimento, 105 alunos (16,28\%) sabiam da sua existência, mas não a conheciam e $63(9,77 \%)$ afirmaram ter conhecimento. Após a reaplicação dos questionários, o resultado foi de que a maioria ainda não a conhecia (442 alunos, 67,17\%), 158 alunos (24,01\%) sabiam da sua existência sem conhecê-la e 58 alunos $(8,81 \%)$ não a conheciam. Carvalho (2015) também apurou um percentual aproximado (71\%) em seu estudo na UFLA. O resultado do teste estatístico apresentou diferença significativa $(p=0,002)$, evidenciando que as atividades educacionais foram eficientes para esclarecer acerca existência de uma legislação ambiental específica na área de resíduos sólidos, mas é preciso ressaltar que um estudo aprofundado deste dispositivo legal não era um objetivo a ser alcançado pelo projeto.

A estratégia de sensibilização ambiental adotada pelo projeto durante as atividades em salas de aula, a qual incluiu informações sobre quais resíduos podiam ser reciclados, o padrão adotado pela instituição e a necessidade da parceria com as associações de catadores, a partir de uma visão integrada dos meios naturais, sociais, econômicos e culturais, e reflexão sobre os padrões de consumo, possibilitou aos alunos refletirem sobre as causas e consequências da necessidade da segregação correta dos resíduos sólidos. Verificou-se que essa estratégia obteve resultado satisfatório para a população de alunos do câmpus Barbacena. 


\section{Considerações finais}

O resultado obtido pela aplicação do questionário de percepção ambiental, antes e depois das intervenções em sala, permitiu inferir que a comunidade acadêmica responde de forma positiva às atividades de educação ambiental voltada para a temática de resíduos sólidos, o que refletiu na melhoria nas taxas de segregação. Entretanto, a instituição precisa cumprir seu papel de forma mais efetiva, por meio do aprimoramento de seus programas de gestão e gerenciamento de resíduos sólidos e de Educação Ambiental construídos de forma crítica e participativa pela comunidade acadêmica. Além disso, as atividades educacionais devem ser permanentes, pois são essenciais para evitar um declínio da participação inicial da comunidade acadêmica. A criação de uma comissão de coleta seletiva é primordial para a implementação e o diagnóstico regular das necessidades materiais e humanas. Como é um programa que visa modificar os hábitos, portanto, deve ser continuamente melhorado por meio da introdução de indicadores de desempenho. Além disso, o fato de as atividades educacionais não terem abordado todos os possíveis geradores de resíduos sólidos na instituição pode ter afetado negativamente os dados obtidos.

De acordo com Disterheft et al. (2015), as abordagens participativas (como, por exemplo, as intervenções em sala) e as atividades extraclasse são uma oportunidade para uma mudança de paradigma, de forma a repensar a relação entre o homem e os recursos naturais, contribuindo para a integração do conceito de sustentabilidade na cultura universitária. Para estes autores, o sucesso dessas abordagens depende das condições institucionais, como a estrutura disponibilizada para a realização das etapas do gerenciamento de resíduos sólidos, da motivação das pessoas envolvidas, principalmente destacando a importância de habilidades específicas das pessoas responsáveis pela condução das atividades e das competências participativas dos envolvidos no processo. Seu estudo aponta para um conjunto de fatores críticos para que um projeto obtenha resultados positivos, de forma que consiga efetivar e integrar as dimensões da participação social, destacando-se, principalmente, a comunicação efetiva, além de uma estratégia bem definida com objetivos tangíveis para que os participantes possam apoiar a ação. Embora exista um consenso entre os autores no sentido de que a participação e o envolvimento são indispensáveis para melhorar o gerenciamento ambiental, é extremamente complexo e difícil implementar processos participativos que sejam verdadeiramente efetivos. É por isso que existem poucos exemplos de processos participativos dentro de estratégias de gerenciamento ambiental com altos níveis de envolvimento que merecem destaque (CASADO, 2011).

Um aspecto relevante que dificultou a adoção de práticas adequadas para o gerenciamento dos resíduos sólidos foi a grande rotatividade dos colaboradores responsáveis pela limpeza da instituição, oriundos de empresas terceirizadas. Os esforços de sensibilização e treinamentos eram continuamente anulados porque essas pessoas eram continuamente transferidas para diferentes setores. Acredita-se que procedimentos padrões 
relativos à coleta seletiva devem ser adotados, assim como a necessidade de introduzir nos certames licitatórios a necessidade de profissionais na área ambiental.

É importante observar que não há uma orientação prévia aos colaboradores responsáveis pelo serviço, de forma a abordar os procedimentos corretos para que o manejo dos resíduos sólidos produzidos seja adequadamente executado. A complexidade nas diversas tipologias geradas dentro da unidade acadêmica (resíduos recicláveis, compostáveis, de serviço de saúde humana e animal, de laboratórios, de equipamentos eletroeletrônicos, de atividades agrícolas, do setor de laticínios, do abatedouro dentre outros relacionados à própria manutenção da estrutura da instituição, como lâmpadas, entulhos e demolições, podas e de varrição) também é um fator que dificulta a execução correta do gerenciamento dos resíduos sólidos gerados. Essa questão, aliada a atual limitação orçamentária para investir em serviços essenciais e a ausência de um diagnóstico sobre a geração e a caracterização da geração, torna o serviço prestado inadequado e ineficiente.

A sociedade espera que as instituições de ensino ajam de forma responsável em relação ao ambiente e enseja que elas sejam líderes no movimento de proteção ambiental. Especificamente, seria esperado que o câmpus se esforçasse para implantar um sistema de gestão responsável dos resíduos, por questões éticas e por ofertar cursos na área ambiental. Além disso, a gestão apropriada dos resíduos traz benefícios para a instituição, como a redução dos recursos financeiros destinados ao gerenciamento, mas, acima de tudo, seria um exemplo para os alunos e a comunidade acadêmica. Certamente, uma postura proativa dessas instituições na implementação de Sistemas de Gestão Ambiental (SGA) em seus campi, como modelo prático de gestão sustentável para a sociedade auxiliaria muito na resolução de questões relacionadas aos resíduos sólidos. A adoção de práticas sustentáveis pode trazer inúmeros benefícios, como economia de recursos econômicos e redução da pegada de carbono, do desperdício, da poluição e do consumo de energia (PIKE et al., 2003). Se ela não for combinada com uma política ambiental efetiva, com uma legislação rígida (que também seja cumprida) ou com ações voltadas para uma distribuição de renda igualitária, dificilmente ocorrerão mudanças efetivas no comportamento das pessoas e na atual situação socioambiental.

\section{Referências}

BRASIL. Decreto no $\mathbf{5 . 9 4 0}$ de 25 de outubro de 2006. Institui a Coleta Seletiva Solidária pelos órgãos e entidades da administração pública federal direta e indireta, e dá outras providências. Diário Oficial da União, Brasília, DF, 26 out. 2006.

ALSHUWAIKHAT, H. M.; ABUBAKAR, I. An integrated approach to achieving campus sustainability: assessment of the current campus environmental management practices. Journal of Cleaner Production, Londres, v. 16, n. 16, p. 1711-1822, Nov. 2008.

revista brasileira educação ambiental 
BRINGHENTI, J. R.; GÜNTHER, W. M. R. Participação social em programas de coleta seletiva de resíduos sólidos urbanos. Revista Engenharia Sanitária e Ambiental, São Paulo, v. 16, n. 4, p. 421-430, maio 2011.

CARVALHO, F. C. Análise da coleta seletiva em um campus universitário: a percepção ambiental dos discentes na Universidade Federal de Lavras. 2015. 159 p. Dissertação (Mestrado em Tecnologia e Inovações Ambientais) Universidade Federal de Lavras, Lavras, 2015.

CARVALHO, V. S. A ética na Educação Ambiental e a ética da Educação Ambiental. In: MACHADO, C. et al. Educação Ambiental consciente. 2. ed. Rio de Janeiro: Wak, 2008. p. 52-71.

CASADO, M. Analisis de los procesos de participaci on ambiental en la Universidad Autonoma de Madrid. In: CANO, L. et al. (Org.). Nuevas investigaciones iberoamericanas en educacion ambiental. São Carlos: Ed. USP, 2011. p. 167- 190.

DIAS-ROCHA, P. E.; MASSAMBANI, O. A coleta seletiva do lixo na USP: ações por um campus sustentável. Anais do Encontro Latino Americano de Universidades Sustentáveis, Passo Fundo: Universidade de Passo Fundo, 2008. CD-ROM.

DISTERHEFT, A. et al. Sustainable universities - a study of critical success factors for participatory approaches. Journal of Cleaner Production, London, v. 106, n. 53, p. 11-21, Nov. 2015.

KARATZOGLOU, B. An in-depth literature review of the evolving roles and contributions of universities to education for sustainable development. Journal of Cleaner Production, Londres, v. 49, p. 44-53, June 2013.

LANSANA, F. M. Distinguishing potential recyclers from nonrecyclers: a basis for developing recycling strategies. Journal of Environmental Education, Victoria, v. 23, n. 2, p. 16-23, 1992.

MALAKAHMAD, A.; ZA, M.; NASIR, M. Solid waste characterization and recycling potential for University Technology PETRONAS Academic Buildings. American Journal of Environmental Sciences, Los Angeles, v. 6, n. 5, p. 422- 427, June 2010.

MUKAKA, M. M. A guide to appropriate use of correlation coefficient in medical research. Malawi Medical Journal, Malawi, v. 24, n. 3, p. 69-71, Sept. 2012.

NEVES, A. C. R. R.; CASTRO, L. O. de A. Separação de materiais recicláveis: panorama no Brasil e incentivos à prática. Revista Eletrônica em Gestão, Educação e Tecnologia Ambiental, Santa Maria, v. 8, n. 8, p. 1734-1742, set./dez. 2012.

NITHYA, A. R.; VELUMANI, A.; SENTHI, K. Optimal location and proximity of municipal solid waste collection bin using GIS: case study of coimbatore city. Waste Transactions on Environment and Development, Amsterdam, v. 4, n. 8, p. 107-119, Oct. 2012.

Revbea, São Paulo, V. 14, № 1: 456-477, 2019. 
OLIVEIRA, M. G. R. et al. A importância da Educação Ambiental na escola e a reciclagem de lixo orgânico. Revista Científica Eletrônica de Ciências Sociais Aplicadas da Eduvale, Jaciara, v. 5, n. 7, p. 1-20, nov. 2012.

PIKE, L. et al. Science education and sustainability initiatives: a campus recycling case study shows the importance of opportunity. International Journal of Sustainability in Higher Education, West Yorkshire, v. 4, n. 3, p. 218-229, Sept. 2003.

QUEIROZ, A. P. B.; PEDRINI, A. G. Percepção ambiental de moradores de condomínios no município de Niterói, estado Rio de Janeiro, Brasil sobre resíduos sólidos urbanos associados a sua coleta seletiva. Revista Eletrônica do Mestrado em Educação Ambiental, Porto Alegre, v. 31, n. 2, p. 15171256, jul./dez. 2014

SOARES, J. A. S.; PEREIRA, S. S.; CÂNDIDO, G. A. Gestão de resíduos sólidos e percepção ambiental: um estudo com colaboradores do campus I da Universidade Estadual da Paraíba. Saúde e Meio Ambiente, Três Lagoas, v. 4, n. 1, p. 39-54, jan./jul. 2017.

TAVARES, A. A construção da autoestima. Educar para Crescer, São Paulo, v. 12, p. 47, set. 2013.

ZAGO, V. C. P. et al. Análise da percepção dos servidores administrativos (Campus II) do Centro Federal de Educação Tecnológica de Minas Gerais sobre o programa de coleta seletiva solidária. Juiz de Fora: COBENGE, 2014. 7 p.

ZHANG, H.; JIONG, L.; ZONG-GUO, W. College students municipal solid waste source separation behavior and its influential factors: a case study in Beijing, China. Journal of Cleaner Production, Londres, v. 164, p. 44-54, 2017. 